\title{
Acute hemiconcern: a right anterior parietotemporal syndrome
}

\author{
J Bogousslavsky, E Kumral, F Regli, G Assal, J Ghika
}

\begin{abstract}
Three patients developed a striking visual and motor behaviour in the acute phase of a stroke involving the territory of the right anterior parietal artery (postcentral gyrus, parts or upper and middle temporal gyri, anterior part of inferior parietal gyrus, and supramarginal gyrus). The patients concentrated on the left side of their bodies, looking at it for long periods and relentlessly rubbing, touching, pinching, pressing, lifting, and manipulating parts of the left arm, trunk, and leg with their right hand or foot. They all had severe loss of elementary sensation on the left (touch, pain, temperature, vibration, position). The behaviour was not associated with overinterest in the left hemispace apart from their own bodies. It lasted no more than a few days, disappearing when left sided sensation improved. The findings suggest an association between sensory dysfunction and this "acute hemiconcern". None of 13 patients with a mirror infarct in the left hemisphere and none of 38 patients with acute hemisensory loss due to thalamic capsular or brainstem stroke showed hemiconcern behaviour. This behaviour may result from a feeling of strangeness critically associated with hemisensory loss without hemispatial neglect, due to involvement of the right anterior parietotemporal region.
\end{abstract}

$(\Im$ Neurol Neurosurg Psychiatry 1995;58:428-432)

Keywords: acute hemiconcern; anterior parietotemporal syndrome

Department of

Neurology, University

Hospital, 1011

Lausanne, Switzerland

J Bogousslavsky

E Kumral

F Regli

J Ghika

Division of

Neuropsychology,

University Hospital,

1011 Lausanne,

Switzerland

G Assal

Correspondence to:

Dr J Bogousslavsky,

Department of Neurology,

University Hospital, 101

Lausanne, Switzerland.

Received 17 June

and in revised form

23 September 1994

Accepted 3 November 1994 selective and profound interest in the opposite side of the body in association with severe sensory loss: the patients touched, manipulated, and looked at the left side of their body in a relentless and sometimes compulsive manner. This activity lasted only a few days and improved as sensation returned. For these reasons, we called this behaviour "acute hemiconcern".

\section{Patients}

We identified three patients with acute "hemiconcern" for the side of the body opposite to infarction in one cerebral hemisphere. These patients were identified from more than 2500 patients with first ever stroke who were admitted consecutively to our population based primary care centre, and were in the Lausanne Stroke Registry. ${ }^{8}$ Although selection was made retrospectively from the Registry data, the three patients had been examined by at least one senior author (JB or FR).

All three patients showed the same type of behaviour when admitted to hospital: they looked overinterested in and overconcerned about the left side of their bodies, which had moderate to severe sensory loss (involving light touch, vibration, and position sensation, and in two, also pain and temperature sensation); they stared for several seconds at various parts of their left side and rubbed, pressed, and manipulated their trunk, face, and limbs on the left with their right hand; sometimes, they also lifted and displaced their left arm or leg with their right hand. It was difficult to distract them from this activity, which was relentless during the first hours of admission. Although two patients complained of numbness, none had painful or itching paraesthesiae to explain the rubbing activity. They could not give a satisfactory explanation for their concern, interest, and manipulation of their left side, except that it felt "strange". They showed no particular overinterest in the left hemispace, their activity being concentrated on the left side of their own bodies. Neuropsychological testing in the acute phase and a few days later showed no appreciable dysfunction; in particular, no sign of visual hemineglect was found on line bisection or cancellation tests. One patient showed left ear extinction on a dichotic listening test, which resolved after three days. The hemiconcern behaviour was transient, being limited to the first two to six days after stroke. Its improvement and disappearance paralleled improvement in left sided sensation. 
Brain MRI (two patients) or CT (one patient) showed an acute infarct in the anterior parietal region (and upper parts of temporal lobe) on the right in all three patients (figure), which corresponded to the territory of the anterior parietal artery..$^{9-12}$ From the registry, we identified two other patients with a right anterior parietal artery territory infarct of similar topography and size, in whom this behaviour was not reported. None of a total of 13 patients with an infarct in the territory of the left anterior parietal artery identified during the same period showed hemiconcern behaviour. It was also not reported in 38 patients with hemisensory loss due to right or left thalamic (32), brainstem (five), or capsular stroke (one).

PATIENT 1

A 66 year old man was admitted to hospital after he developed left sided numbness, predominant in the hand. His history included high cholesterol concentrations, cigarette smoking (20 packs a year), and compensated heart failure. The day of admission, he had had an unpleasant numbness in his left hand while driving his car. This spread to the left side of his body within a few minutes. He stopped and fell to his left when trying to get out of the car. On admission one hour later, the patient was anxious and slightly agitated. $\mathrm{He}$ relentlessly manipulated and touched his left hand and forearm, to a lesser extent his left leg and the left side of his trunk, less often his foot-with his right hand-in a rather stereotyped manner; he palpated, rubbed, pinched, and pressed on the skin, muscles, and bones at different spots on his left arm and leg, attentively looking at what he was doing. It was very difficult to distract him from this activity. When asked why he was behaving in that way, he was not able to give a clear explanation, but stated that his left side was numb and "felt strange", and that he had to take care of it. It was possible to examine him and to perform the usual bedside neurological and neurophysiological tests, but this was always interrupted by his manipulating, touching, and looking at the left side of his body. On neurological examination, there was a moderate left lower facial weakness, with decreased light touch, pain, and temperature sensation on the left side of the face, mouth, tongue, and palate. The left corneal reflex was decreased. Visual fields and eye movements were normal. The patient did not move the limbs on the left spontaneously. Tone in the arm and leg on the left was decreased, with decreased tendon reflexes, and no plantar reflex on that side. There was a complete anaesthesia in the left side of the trunk, and left arm and leg, involving pain, light touch, temperature, vibration, and position. There was no abnormality on the line bisection test (line bisection at $14.5,14.5,15,16,15.5 \mathrm{~cm}$ from the right edge of lines $30 \mathrm{~cm}$ long on five trials) or cancellation test $(20 / 20)$. There was no left extinction on simultaneous right and left auditory or visual stimulation. The next day, the manipulatory behaviour of the left
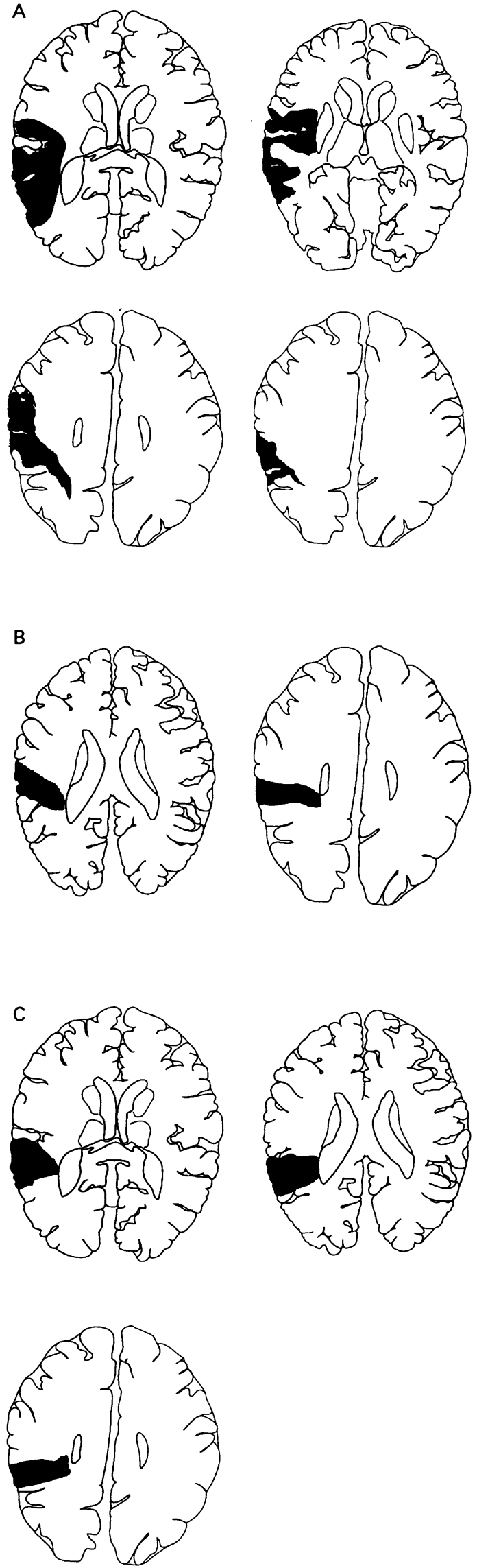

Templates of infarct shown by MRI (patients $1(A)$ and $3(C)$ ), or $C T$ (patient 2(B)).

side was still present, but intermittently, and the patient could now move the limbs spontaneously. Sensation had improved, although 
the patient stated that his left side still felt numb and strange. He never complained of feeling a foreign body instead of his left body side or of a feeling of amputation. On neuropsychological examination with a standard battery of tests (Assal G Batterie des examens neuropsychologiques du CHUV, Lausanne, Switzerland, 1985) - namely, tests for language (fluency, Boston naming test, token test, repetition, writing, reading), bucco-lingualfacial and limb apraxias, gnosias (famous faces, colours, objects, finger, right-left), visuospatial and visuoconstructive tasks (drawing a cube, Poppelreuter, orientation on a map), memory (digit span, Corti test, learning and recall of series of words and images), frontal functions (fist-ring, fist-palm-side tests, Stroop test), and neglect (line bisection test, cancellation test, simultaneous application of stimuli) showed normal results.

Extracranial and transcranial Doppler ultrasounds showed no abnormality. Brain CT on admission was normal. Brain MRI six days after stroke showed an infarct in the territory of the right anterior parietal artery involving (mapped as described by Duvernoy ${ }^{13}$ ) the postcentral gyrus, the anterior part of the inferior parietal gyrus $\left(P_{2}\right)$, and supramarginal gyrus, and parts of the superior and middle temporal gyri (figure, A). Standard blood tests and ECG were unremarkable.

During the week after admission, sensation improved progressively on the left and the attention and concern of the patient for his left side decreased. The only remaining motor difficulty was dysmetria of the left arm and leg without visual control (proprioceptive ataxia). $\mathrm{He}$ remembered that he had been overconcerned by his left body side, and had "had to take care of it and exercise it", but without further explanation. $\mathrm{He}$ was discharged 13 days after his stroke.

\section{PATIENT 2}

A 62 year old widow developed right frontal headaches with numbness and weakness in her left arm and leg. She had a long history of hypertension and type II diabetes. On admission, she was relentlessly rubbing her left arm, abdomen, legs, and face with her right hand and heel. At times, she was also intensely and carefully looking at different parts of her body on the left. When asked about this behaviour, she did not explain it but said that she had "to concentrate" on her left side because she could not feel it properly. Later, she said that she had to rub it, so that it would "not be sick anymore". On examination, there was a slight lower facial weakness on the left. Light touch, pain, and temperature sensations were abolished on the left side of the face, mouth, tongue, and palate. There were no abnormalities of visual field and eye movements. The patient did not move the limbs on the left spontaneously, but on repeated stimulation motor strength seemed normal. Her left arm and leg were grossly unstable when outstretched, with abduction and elevation when her eyes were closed. There was dysmetria without oscillations at the finger to nose and heel to knee tests with the eyes closed. Muscle tone and tendon reflexes were normal. Light touch, pain, temperature, vibration, and position sensations were abolished on the left side of her trunk (with a sharp cut off point at the midline), and left arm and leg. Neuropsychological examination (the same day and two days later) with the same battery of tests as in patient 1 showed no appreciable abnormality. In particular, the line bisection test (the same test as in patient 1), cancellation test $(20 / 20)$, and Gainotti's recognition test were normal.

On admission CT was normal, but one week later it showed an infarct in the territory of the right anterior parietal artery, involving the cortex and subcortical white matter at the level of the postcentral gyrus, upper parts of the superior temporal gyrus, and most anterior part of the inferior parietal $\left(\mathrm{P}_{2}\right)$ and supramarginal gyri (figure, $B$ ). Findings from extracranial and transcranial Doppler, echocardiography, ECG, and standard blood tests were normal. Somatosensory evoked potentials (median nerve stimulation) showed an absence of suprathalamic-parietal response.

Within a few days of admission, left sided sensation had improved considerably with concomitant improvement in limb coordination on that side. The patient continued to examine and manipulate the left side of her body intermittently for two days, and then this behaviour stopped. When discharged three weeks after stroke, the patient could use her left arm and leg normally under visual control, but some proprioceptive lack of coordination still occurred on eye closure. Light touch, pain, temperature, and position sensation remained decreased over the left side.

\section{PATIENT 3}

A 62 year old clerk was admitted because he was looking "strange" at his office. He had been treated for over 10 years for hypertension and type II diabetes. On admission, he was slightly disoriented in time and place. $\mathrm{He}$ was apparently not concerned at all by the surroundings, nurses, or doctors, but he was occupied with a continuous activity that consisted of caressing his face and trunk on the left, and lifting and rubbing his left arm and leg with his right hand. $\mathrm{He}$ was staring for periods of over 10 seconds at various places on the left side of his body. This activity was difficult to interrupt for the purpose of neurological examination. The patient could not explain his behaviour, but stated that "something was wrong", without further details. On examination, there was a partial left inferior quadrantanopia. Eye movements were normal. There was no facial asymmetry and sensation in the face, mouth, tongue, and palate seemed normal. The patient did not move his left arm and leg spontaneously but he could lift them when asked. There was a slow elevation of the outstretched upper limb on the left, with flexion of the palm and instability of the fingers. There was a moderate dysmetria on the finger to nose and heel to knee tests on the left with the eyes closed. Pain and 
temperature sensation seemed preserved, but light touch and vibration sensation were decreased on the left side (trunk and limbs). Position sensation was also decreased in the fingers and toes on the left. On neuropsychological testing (the same battery as in patients 1 and 2), there was a left ear extinction on the dichotic listening test, but the line bisection test (the same test as in patients 1 and 2), and the cancellation test $(20 / 20)$ were normal; no other abnormality was found. Three days later, neuropsychological examination was normal, including the dichotic listening test.

On admission CT was normal, but six days later MRI showed an infarct in the territory of the right anterior parietal artery, involving the posterior aspect of the postcentral gyrus, upper parts of the superior temporal gyrus, and the anterior part of the inferior parietal gyrus $\left(\mathbf{P}_{2}\right)$ and supramarginal gyrus (figure, C). Doppler ultrasounds and cerebral angiography showed a $95 \%$ stenosis of the right internal carotid artery.

The patient showed considerable improvement over two days, and his behaviour and interest in the left side of his body ceased. The only remaining abnormality was left extinction on light touch or pain and simultaneous double stimulation of the hands. $\mathrm{He}$ was referred for carotid endarterectomy 20 days after stroke.

\section{Discussion}

Although rare in acute stroke $(<0 \cdot 2 \%)$, the hemiconcern behaviour seen in our patients seemed specific for involvement of the anterior parietal artery territory on the right. It is interesting that it was not present in any patient with stroke in a similar part of the left cerebral hemisphere, or in patients with sensory stroke due to involvement of the thalamus or another region of the brain. The infarcts in our three patients with acute hemiconcern behaviour were similar, being centred on the postcentral gyrus, superior temporal gyrus, and anterior part of the inferior parietal and supramarginal gyri, and involved both the cortex and underlying white matter. We emphasise that more posterior parts of the parietal lobe (inferior parietal lobule), which have been incriminated classically in hemineglect, ${ }^{26}$ were spared. Indeed, our patients showed no or little evidence for coexisting spatial hemineglect. On the other hand, their hemiconcern behaviour could not be considered as a positive mirror form of spatial hemineglect, because their interest and activity were limited to the left side of their own body and did not involve the surrounding hemispace. Our patients also showed features of motor hemineglect. They did not move the limbs on the left spontaneously except after repeated encouragements. Because they were aware of their left sided sensory loss, and because of motor neglect, they may have been unable to initiate left upper and lower limb movements to explore their affected side, which accentuated the aspect of unilateral manipulative behaviour. The hemiconcern behaviour may also represent an uncommon sensory dependent form of the hyperkinetic motor behaviours that have been reported on the "good side" of the body in acute stroke with hemiplegia. ${ }^{7}$ Such an excess movement of the right upper and lower limbs ("motor allochiria") seems an unlikely explanation, however, because the motor behaviour developed as a reaction to acute changes of sensation in the contralateral side of the body.

Actually, as supported by the clinical evolution in our patients, the hemiconcern behaviour was closely linked to left sensory loss, as both disturbances improved in parallel. Sensory loss in itself cannot fully explain the hemiconcern behaviour, because none of the patients with sensory stroke but a different lesion topography showed it. Our patients did not show any of the sensory dysfunctions sometimes associated with sensory stroke, such as central pain, alloaesthesia-allochiria, tactile agnosia, asymbolia for pain, or delusions such as supernumerary phantom limb. ${ }^{14-20}$

Also, sensory loss was not of the "cortical" type (isolated loss of discriminative sensation, stereoaesthesia, and graphaesthesia), but was consistent with a pseudothalamic sensory syndrome (involvement of elementary sensation: touch, pain, temperature, vibration, position $)^{12}$ in agreement with the anterior parietal location of the lesion involving somatosensory area I and underlying white matter. ${ }^{9-12}$ The fact that hemiconcern behaviour may be associated with parietal stroke leading to pseudothalamic sensory loss, but not with thalamic sensory stroke, highlights the role of the anterior parietal lobe in the genesis of this behavioural abnormality. It may be related in part to some feeling of strangeness, which the patients were unable to report or to detail properly, but which could have acted as a stimulus for them to check the presence, aspect, and consistency of their left body side. With respect to anxiety shown by at least two of our patients, their lack of anosognosia must be emphasised. In a way, the hemiconcern behaviour could even be viewed as a mirror image of anosodiaphoria, which corresponds to lack of concern for the hemiparetic side. The specificity for right sided infarction is also stressed, because it suggests a right-left hemisphere difference, as for hemineglect. ${ }^{1-6}$ In more severe stroke encompassing the anterior parietal artery territory but also involving more posterior parts of the right parietal lobe, including severe damage to the inferior parietal lobule, hemineglect and anosognosia may become the prominent behavioural dysfunctions. Thus lesions limited to the right anterior parietotemporal region may be necessary for hemiconcern behaviour to occur, by leading to hemisensory loss with a feeling of strangeness in the absence of hemispatial neglect.

Together with motor impersistence, ${ }^{21}$ asymmetric catalepsy ${ }^{22}$ or motor persistence, response to next patient stimulation, ${ }^{23}$ acute confusional state, ${ }^{24-26}$ and other dysfunctions, ${ }^{27} 28$ hemiconcern behaviour may represent another uncommon but localising acute 
behavioural consequence of stroke in the right hemisphere.

We thank Dr T Landis, Geneva, for helpful comments on a first version of this paper.

1 Mesulam M-M. A cortical network for directed attention and unilateral neglect. Ann Neurol 1981;10:309-25.

2 Heilman KM. Localization of lesions in neglect. In: Kertesz A, ed. Localization in neuropsychology. New York: Academic Press, 1983:471-92.

3 Calvanio R, Petrone PN, Levine DN. Left visual spatia neglect is both environment-centred and body-centred. Neurology 1987;37:1179-83.

4 Binder J, Marshall R, Lazar R, Benjamin J, Mohr JP. Distinct syndromes of hemineglect. Arch Neurol 1992;49:1 187-94

5 Small N, Ellis S. Brief remission periods in visuospatial neglect: evidence from long-term follow-up. Eur Neurol neglect: evidence

6 Vallar G, Perani D. The anatomy of unilateral neglect after right-hemisphere stroke lesions. A clinical/CT scan correlation study in man. Neuropsychologia 1986;24:609-22.

7 Ghika J, Bogousslavsky J, Van Melle G, Regli F Hyperkinetic motor behaviors contralateral to hemiplegia in acute stroke. Eur Neurol 1995;35:27-32.

8 Bogousslavsky J, Van Melle G, Regli F, for the Lausanne Stroke Registry Group. The Lausanne Stroke Registry: analysis of 100 consecutive patients with first stroke. Stroke 1988;19:1083-92.

9 Foix C, Chavany JA, Lévy $M$. Syndrome pseudothalamique d'origine pariétale. Lésion de l'artère du sillon interpariétal ( $\mathrm{Pa} \mathrm{P}_{1} \mathrm{P}_{2}$ antérieures, petit territoire insulocapsulaire). Rev Neurol 1927;35:68-76.

10 Bogousslavsky J, Assal G, Regli F. Aphasie afférente motrice et hémisyndrome sensitif droit. Le syndrome de 1982;138:644-55.

11 Bogousslavsky J, Van Melle G, Regli F. Middle cerebra artery pial territory infarcts: a study of the Lausann Stroke Registry. Ann Neurol 1989;25:555-60.

12 Bassetti C, Bogousslavsky J, Regli F. Sensory syndromes in parietal stroke. Neurology 1993;43:1942-9.

13 Duvernoy $\mathrm{H}$. The human brain. Surface, three-dimensional sectional anatomy and MRI. Wien: Springer-Verlag, 1991.

14 Critchley M. The parietal lobes. New York: Hafner, 1953.

15 Pause M, Kunesch E, Binkofski F, Freund HJ Sensorimotor disturbances in patients with lesions of the parietal cortex. Brain 1989;112:1599-625.

16 Michel D, Laurent B, Convers $P$, et al. Etude clinique, électrophysiologique et topographique de 12 cas. Rev Neurol 1990;146:405-14.

17 Masson C, Koskas P, Combier J, Masson M. Syndrome cortical pseudothalamique gauche et asymbolie à la douleur. Rev Neurol 1991;147:668-70.

18 Schmahmann JD, Leifer D. Parietal pseudothalamic pain syndrome. Clinical features and anatomic correlates. Arch Neurol 1992;49:1032-7.

19 Caselli RJ. Ventrolateral and dorsomedial somatosensory association cortex damage produces distinct somesthetic syndromes in humans. Neurology 1993;43:762-71.

20 Halligan PW, Marshall JC, Wade DT. Three arms: a case study of supernumerary phantom limb after right study of supernumerary phantom limb after right 56:159-66.

21 Fisher CM. Left hemiplegia and motor impersistence. 7 Nerv Ment Dis 1956;123:201-18.

22 Saver JL, Greenstein P, Ronthal M, Mesulam MM Asymmetric catalepsy after right hemisphere stroke. Mov Dis 1993;8:62-73.

23 Bogousslavsky J, Regli F. Response-to-next-patientstimulation: a right hemisphere syndrome. Neurology 1988;38:1225-7.

24 Mesulam M-M, Waxman SG, Geschwind N, Sabin T Acute confusional states with right middle cerebral artery infarctions. 7 Neurol Neurosurg Psychiatry 1976:39. 84-9.

25 Caplan LR, Kelly M, Kase CS, et al. Infarcts of the inferior division of the right middle cerebral artery: mirror image of Wernicke's aphasia. Neurology 1986;36:1015-20.

26 Mori E, Yamadori A. Acute confusional state and acute agitated delirium. Occurrence after infarction in the agitated delirium. Occurrence after infarction in
right MCA territory. Arch Neurol 1987;44:1139-43.

27 Hier DB, Mondlock J, Caplan LR. Behavioral abnormalities after right hemisphere stroke. Neurology 1983;33 337-44.

28 Bogousslavsky J. Syndromes majeurs de l'hémisphère mineur. Encyclopédie médico-chirurgicale (Neurologie) 1991;17022 E $\mathbf{E}^{10}, 1-6$. 